\title{
Pengembangan Alat Ukur Total Dissolved Solid (TDS) Berbasis Mikrokontroler Dengan Beberapa Variasi Bentuk Sensor Konduktivitas
}

\author{
Harum Cahyani", Harmadi, Wildian \\ Jurusan Fisika, Universitas Andalas \\ Laboratorium Elektronika dan Instrumentasi, Jurusan Fisika, Universitas Andalas, Padang \\ *harumcahyani@gmail.com
}

\begin{abstract}
ABSTRAK
Pengembangan alat ukur total dissolved solid (TDS) berbasis mikrokontroler dengan beberapa variasi bentuk sensor konduktivitas telah dilakukan. Penelitian ini untuk mengetahui pengaruh bentuk elektroda sensor konduktivitas dalam pengukuran TDS. Bentuk elektroda yang digunakan yaitu silinder pejal, silinder berongga, dan plat tipis. Nilai error hasil pengukuran nilai TDS dengan menggunakan elektroda silinder pejal, silinder berongga dan plat tipis berturut-turut dibandingkan dengan alat acuan TDS meter EZ-1 adalah 6,65\%, 8,69\% dan 3,83\%. Berdasarkan hasil uji dan analisis data diperoleh hasil pengukuran TDS dengan menggunakan elektroda berbentuk plat tipis lebih akurat dibandingkan dengan kedua bentuk elektroda lainnya. Perubahan temperatur (dari $25^{\circ} \mathrm{C}$ hingga $84^{\circ} \mathrm{C}$ ) pada air minum kemasan yang digunakan sebagai sampel menyebabkan nilai TDS berfluktuasi antara $18 \mathrm{ppm}$ hingga $24 \mathrm{ppm}$.

Kata kunci : total dissolved solid (TDS), sensor konduktivitas, mikrokontroler.
\end{abstract}

\section{ABSTRACT}

A development of microcontroller-based total dissolved solid (TDS)-meter using various shapes of conductivity sensor has been conducted. This research aim was to investigate the influence of the shapes of conductivity sensor electrode in TDS measurement. The electrode shapes which were used are a solid cylinder, a hollow cylinder, and a thin plate. The error of TDS measurement using solid cylinder, a hollow cylinder and a thin plate compared to TDS meter type EZ-1 are 6.65\%, $8.69 \%$ and $3.83 \%$ respectively. Result shows that the TDS measurement using the thin plate electrode is more accurate than the two other electrode shapes. The changes of temperature of the drinking water samples from $25^{\circ} \mathrm{C}$ to $84^{\circ} \mathrm{C}$ cause the value of the TDS fluctuated between $18 \mathrm{ppm}$ to $24 \mathrm{ppm}$.

Kata kunci : total dissolved solid (TDS), conductivity sensor, microcontroller.

\section{PENDAHULUAN}

Air minum yang sehat sangat diperlukan masyarakat. Saat ini banyak masyarakat mengkonsumsi air minum dalam kemasan plastik. Menurut YLKI (2011) sebagian air minum tersebut tidak memenuhi syarat baku mutu yang ditetapkan oleh Kementerian Kesehatan (2010), yaitu tidak berasa, tidak berbau, tidak berwarna, tidak mengandung mikroorganisme yang berbahaya, dan tidak mengandung logam berat. Air minum yang tidak sesuai dengan baku mutu tersebut dapat menimbulkan masalah kesehatan seperti kanker, gangguan pada bayi yang dilahirkan, kerusakan jaringan saraf pusat dan penyakit jantung (Sawyer, 1994).

Salah satu faktor penting dalam menentukan kelayakan air untuk dikonsumsi adalah kandungan total dissolved solid (TDS) dalam air. TDS adalah jumlah material yang terlarut di dalam air. Material ini dapat berupa karbonat, bikarbonat, klorida, sulfat, fosfat, nitrat, kalsium, magnesium, natrium, ion-ion organik, senyawa koloid dan lain-lain (WHO, 2003). TDS dapat digunakan untuk memperkirakan kualitas air minum, karena mewakili jumlah ion di dalam air. Nilai baku mutu air terhadap parameter uji TDS yang diperbolehkan menurut standar nasional adalah 1000 mg/L (Kementerian Kesehatan, 2010).

Untuk mengetahui nilai TDS dapat digunakan berbagai teknik pengukuran. Alat standar yang digunakan adalah TDSmeter, namun harganya mahal dan proses pengukurannya lama. Hal ini mendorong beberapa peneliti untuk mengembangkan alat pengukur TDS yang lebih murah dan dengan data real time. Metode yang dapat digunakan untuk mengukur TDS dalam air adalah gravimetri dan konduktivitas listrik. Gravimetri merupakan metode pengukuran TDS yang paling akurat dibandingkan metode yang lainnya. Metode gravimetri dilakukan dengan cara memanaskan sampel sampai cairan sampel diuapkan hingga tersisa residu yang kemudian ditimbang secara langsung dengan menggunakan neraca digital. Dengan demikian didapatkan hasil TDS dari sampel tersebut (Devi dkk, 2013). Konduktivitas Listrik adalah ukuran 
kemampuan suatu bahan untuk menghantarkan arus listrik. Konduktivitas Listrik air secara langsung berhubungan dengan konsentrasi padatan terlarut yang terionisasi dalam air. Konduktansi $(G)$ merupakan kebalikan dari resistansi $(R)$. Setiap bahan mempunyai sifat tertentu yang diungkapkan sebagai hambatan jenis $(\rho)$, dengan satuan ohm meter.

\section{METODE}

\subsection{Alat dan Bahan}

Bahan dan alat yang digunakan dalam perancangan ini yaitu LM35, Arduino Uno atmega328, LCD $16 \times 2$ karakter, rangkaian pembagi tegangan, multimeter, termometer, elektroda sensor konduktivitas (silinder pejal, silinder berongga dan plat tipis). LM35 digunakan sebagai pendeteksi temperatur, Atmega328 digunakan untuk memproses keluaran sensor, LCD 16×2 karakter digunakan sebagai penampil nilai TDS dan temperatur. Elektroda sensor konduktivitas sebagai alat ukur nilai TDS. Sampel yang diuji pada penelitian ini yaitu sepuluh sampel yang merupakan air minum dalam kemasan. Untuk mengukur nilai TDS, masing-masing sampel tersebut divariasikan dengan cara menambahkan garam dapur $(\mathrm{NaCl})$. Sampel yang digunakan divariasikan.

\subsection{Perancangan Diagram Blok Sistem}

Prinsip kerja sensor konduktivitas yaitu dengan dua buah elektroda diberikan arus searah dan didapatkan perubahan nilai konduktivitas listrik dan dibaca nilai tegangan. Elektroda sensor konduktivitas dimasukkan ke dalam sampel air dan data nilai TDS yang terukur ditampilkan pada LCD 16×2 karakter.

Alat ini juga dilengkapi dengan sensor temperatur LM35 untuk memonitor nilai temperatur sampel. Sensor LM35 dilapisi dengan lem silikon agar tidak terjadi hubungan pendek karena sensor akan dimasukkan ke dalam sampel air. Prinsip kerja sensor LM35 yaitu temperatur sampel air diindra oleh komponen LM35 yang peka terhadap temperatur yaitu thermistor lalu data temperatur sampel ditampilkan pada LCD 16×2 karakter. Tahapan kerja alat secara keseluruhan dapat dilihat pada Gambar 1.

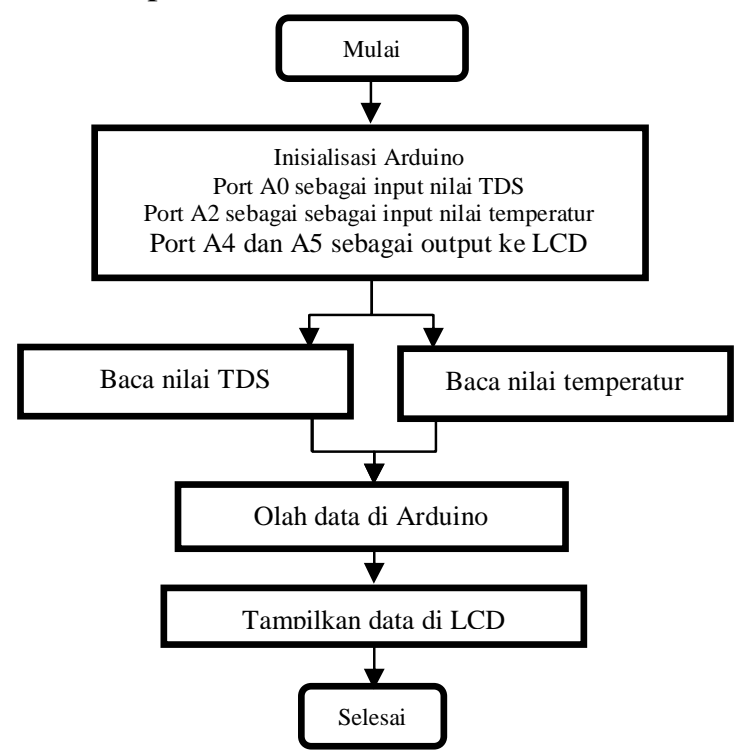

Gambar 1 Tahapan kerja penelitian

Apabila sistem dihidupkan maka arduino akan melakukan inisialisasi terhadap mikrokontroler. Mikrokontroler melakukan pembacaan terhadap nilai ADC yang akan menghasilkan data untuk diproses. Data diproses berdasarkan perhitungan error dan perubahannya pada sistem. Data yang dihasilkan dari keluaran mikrokontroler akan ditampilkan oleh LCD. 


\subsection{Rancangan Bentuk Fisik Alat}

Rancangan Sistem alat ukur TDS terdiri atas rangkaian pembagi tegangan, arduino, sensor konduktivitas, sensor temperatur, dan penampil LCD. Sumber tegangan yang dipakai pada arduino yaitu 5 volt. Rancangan bentuk fisik alat dapat dilihat pada Gambar 2.

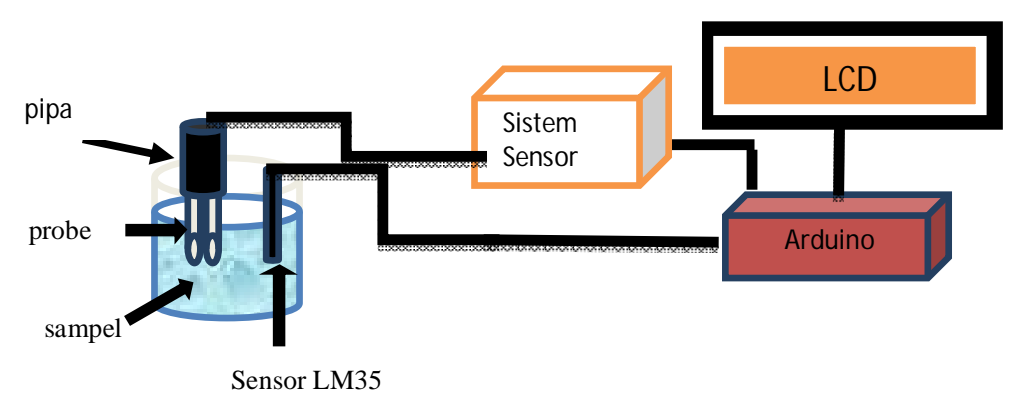

Gambar 2 Rancangan bentuk fisik alat

Nilai tegangan yang terbaca telah diubah kedalam desimal dengan program ADC pada arduino. Selanjutnya didapatkan fungsi transfer dari ketiga bentuk elektroda sensor konduktivitas. Fungsi transfer dari masing-masing elektroda dimasukkan ke dalam program lalu dilakukan pengambilan data. Data sampel yang diambil divariasikan sebanyak sepuluh data. Sampel yang dipakai yaitu sampel memiliki nilai TDS yang bervariasi. Nilai TDS pada sampel divariasikan dengan menambahkan garam dapur $(\mathrm{NaCl})$ yang berbeda pada setiap sampel.

\section{HASIL DAN DISKUSI}

\subsection{Hasil Rancang Bangun Alat}

Bentuk fisik alat yang dihasilkan dapat dilihat pada Gambar 3. Keluaran yang dihasilkan oleh sensor konduktivitas dan sensor temperatur yaitu berupa nilai TDS dan nilai temperatur air minum ditampilkan pada LCD secara bergantian. Nilai TDS didapatkan dari analisis nilai TDS yang terbaca pada TDS meter EZ-1 dengan nilai ADC pada arduino. Melalui pengolahan data baik secara pengukuran maupun secara perhitungan memberikan gambaran tentang karakteristik sistem yang dirancang.

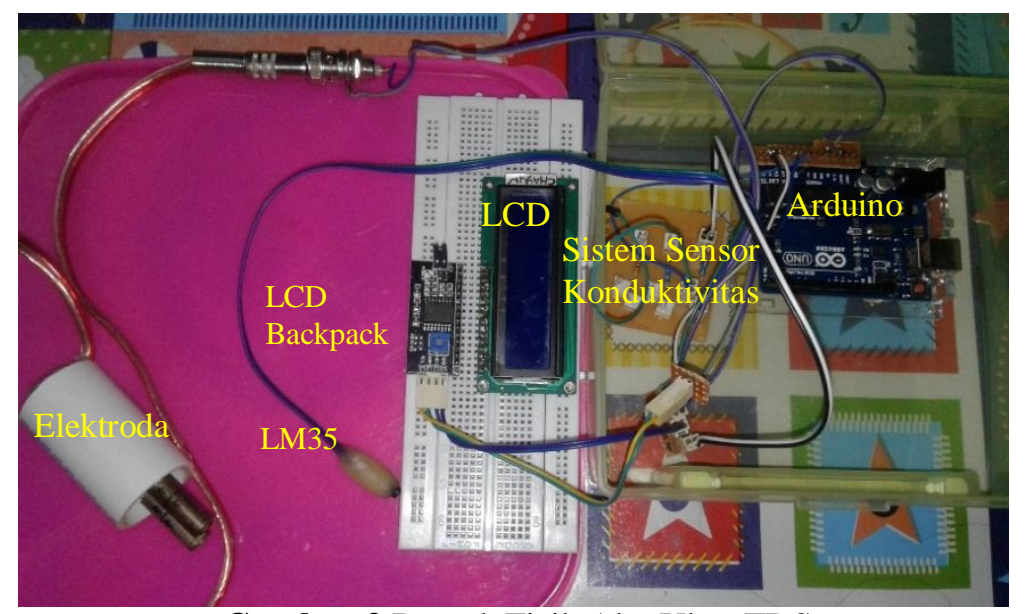

Gambar 3 Bentuk Fisik Alat Ukur TDS

\subsection{Hasil Pengujian Sensor Temperatur}

Dalam melakukan pengukuruan temperatur sensor LM35 dilakukan karakterisasi temperatur terhadap tegangan yang terbaca pada keluaran temperatur. Tegangan keluaran dibaca dengan menggunakan multimeter digital. Temperatur air yang divariasikan dibaca menggunakan termometer digital. Hubungan temperatur pada termometer dan tegangan pada LM35 dapat dilihat pada Gambar 4. 


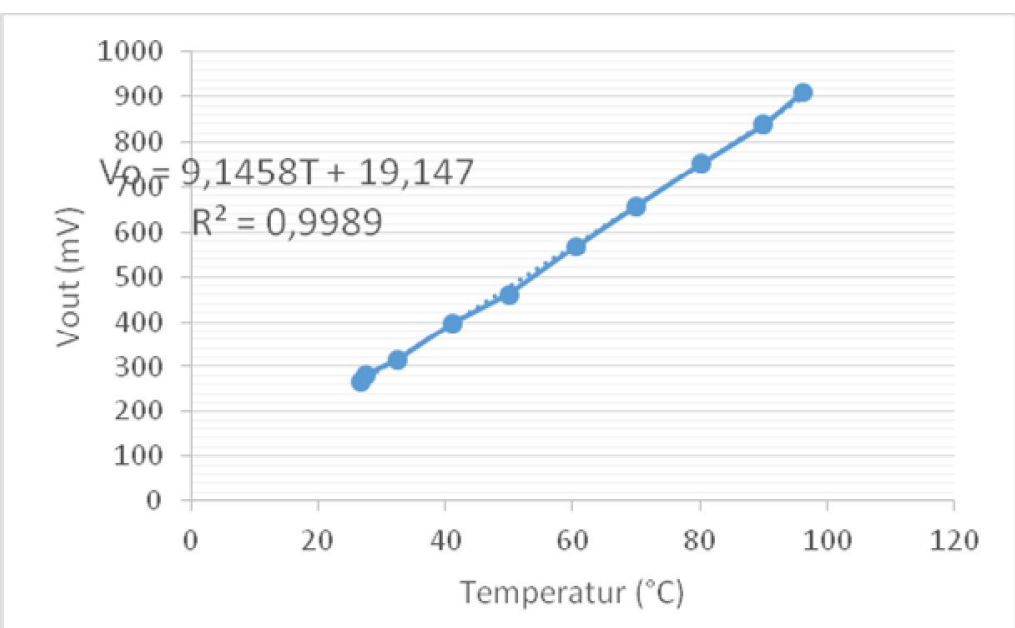

Gambar 4 Grafik hubungan tegangan terhadap temperatur pada LM35

Perbandingan nilai temperatur yang terbaca oleh LM35 dengan temperatur yang terbaca pada termometer acuan dilakukan setelah sensor LM35 dikarakterisasi dan fungsi transfernya dimasukkan ke dalam program yang ditanamkam ke mikrokontroler. Data hasil perbandingan sensor LM35 dengan termometer acuan dapat di lihat pada Tabel 1.

Tabel 1 Perbandingan temperatur LM35 dengan termometer.

\begin{tabular}{ccc}
\hline $\begin{array}{c}\text { Termometer } \\
\left({ }^{\circ} \mathrm{C}\right)\end{array}$ & $\begin{array}{c}\text { Sensor } \\
\text { LM35 } \\
\left({ }^{\circ} \mathrm{C}\right)\end{array}$ & Error \\
\hline 25,00 & 25,03 & $0,12 \%$ \\
30,00 & 29,97 & $0,10 \%$ \\
35,00 & 35,04 & $0,11 \%$ \\
40,00 & 40,02 & $0,05 \%$ \\
45,00 & 45,15 & $0,33 \%$ \\
50,00 & 50,16 & $0,32 \%$ \\
55,00 & 55,01 & $0,02 \%$ \\
60,00 & 60,15 & $0,25 \%$ \\
65,00 & 65,09 & $0,14 \%$ \\
70,00 & 70,00 & $0,00 \%$ \\
\hline Jumlah Error & $1,44 \%$ \\
\hline Error rata-rata & $0,14 \%$ \\
\hline
\end{tabular}

\subsection{Hasil Perancangan Sensor Konduktivitas}

Sensor konduktivitas dirancang dengan 3 (tiga) variasi bentuk elektroda seperti ditunjukkan pada Gambar 5. Nilai TDS yang diindera oleh masing-masing sensor dapat dibandingkan jika luas permukaan sentuhnya terhadap larutan dibuat sama. Oleh sebab itu nilai kedalaman elektroda yang dibenamkan ke dalam larutan harus dihitung terlebih dahulu. Hasil perhitungan menunjukkan bahwa untuk silinder pejal, silinder berongga, dan plat tipis didapatkan kedalaman pembenaman berturut-turut sebesar $4 \mathrm{~cm}, 1,33 \mathrm{~cm}$, dan $3,51 \mathrm{~cm}$ dengan luas permukaannya sebesar $7,82 \mathrm{~cm}^{2}$.

Hubungan TDS terhadap nilai keluaran ADC (yang telah dikonversi ke bentuk desimal) dapat dilihat pada Gambar 6. Pengukuran nilai keluaran ADC yang terbaca pada alat penelitian dibandingkan dengan nilai TDS pada alat acuan. 


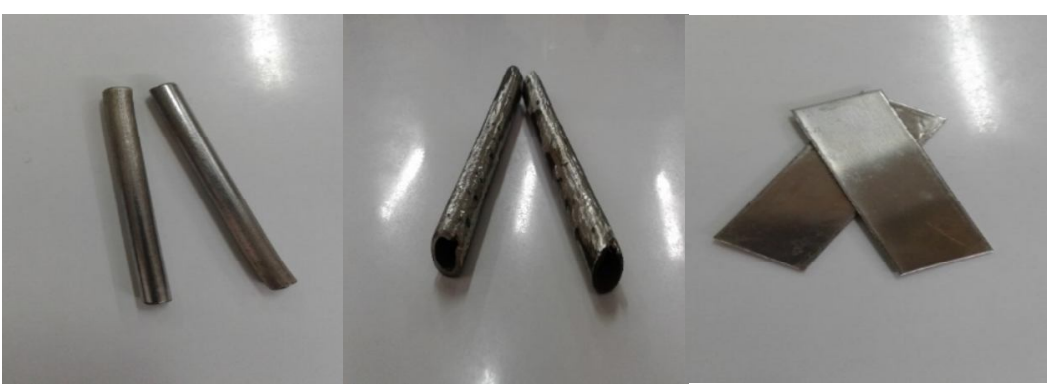

(a)

(b)

(c)

Gambar 5 Rancangan elektroda (a) silinder pejal, (b) silinder berongga, dan (c) plat tipis.

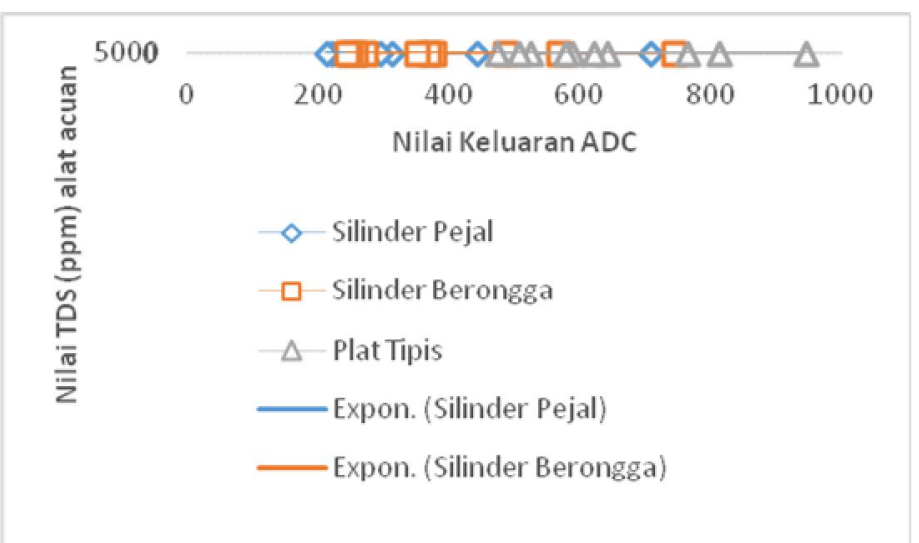

Gambar 6 Grafik hubungan nilai TDS alat acuan terhadap nilai keluaran ADC

Gambar 6 memperlihatkan bahwa hubungan nilai TDS terhadap nilai keluaran ADC berbentuk eksponensial. Fungsi transfer dan derajat korelasi antara data pengukuran dan kecenderungan garis fungsi yang paling cocok masing-masing diperlihatkan pada Tabel 2.

Tabel 2 Fungsi transfer dan derajat korelasi beberapa bentuk sensor konduktivitas.

\begin{tabular}{llll}
\hline No. & $\begin{array}{l}\text { Bentuk elektroda sensor } \\
\text { konduktivitas }\end{array}$ & Fungsi transfer & Derajat korelasi \\
\hline 1 & Silinder Pejal & TDS $=10527 e^{-0.009 \mathrm{x}}$ & $\mathrm{R}^{2}=0,9537$ \\
2 & Silinder Berongga & $\mathrm{TDS}=14785 e^{-0.008 \mathrm{x}}$ & $\mathrm{R}^{2}=0,9941$ \\
3 & Plat Tipis & $\mathrm{TDS}=193598 e^{-0.009 \mathrm{x}}$ & $\mathrm{R}^{2}=0,9701$ \\
\hline
\end{tabular}

$x=$ nilai keluaran ADC yang telah dikonversi ke bentuk desimal.

\subsection{Hasil Akhir Pengukuran dan Pengolahan Data}

Pengukuran nilai TDS dilakukan dengan sepuluh variasi sampel dengan tiga bentuk elektroda sensor konduktivitas. Hasil ukur TDS pada masing-masing bentuk elektroda sensor konduktivitas dibandingkan dengan alat ukur acuan TDS meter EZ-1 dapat dilihat pada Tabel 3. 


\begin{tabular}{|c|c|c|c|c|c|c|}
\hline $\begin{array}{c}\text { Silinder } \\
\text { Pejal }\end{array}$ & $\begin{array}{l}\text { TDS (ppm) } \\
\text { Silinder } \\
\text { Berongga }\end{array}$ & Plat Tipis & $\begin{array}{l}\text { TDS } \\
\text { meter } \\
(\mathrm{ppm})\end{array}$ & $\begin{array}{c}\text { Error } \\
\text { Silinder } \\
\text { Pejal }\end{array}$ & $\begin{array}{c}\text { Error } \\
\text { Silinder } \\
\text { Berongga }\end{array}$ & $\begin{array}{c}\text { Error } \\
\text { Plat Tipis }\end{array}$ \\
\hline 95,75 & 89,31 & 92,52 & 92,00 & $4,08 \%$ & $2,92 \%$ & $2,11 \%$ \\
\hline 180,70 & 163,43 & 180,84 & 171,00 & $5,67 \%$ & $4,43 \%$ & $11,99 \%$ \\
\hline 266,60 & 266,67 & 243,19 & 242,00 & $10,17 \%$ & $10,19 \%$ & $2,06 \%$ \\
\hline 355,93 & 374,81 & 365,74 & 307,00 & $15,94 \%$ & $22,09 \%$ & $3,36 \%$ \\
\hline 442,00 & 423,12 & 419,52 & 417,00 & $6,00 \%$ & $1,47 \%$ & $5,65 \%$ \\
\hline 475,07 & 471,79 & 522,58 & 547,00 & $13,15 \%$ & $13,75 \%$ & $2,54 \%$ \\
\hline 645,52 & 643,53 & 639,61 & 646,00 & $0,07 \%$ & $0,38 \%$ & $3,93 \%$ \\
\hline 773,04 & 737,88 & 770,03 & 769,00 & $0,53 \%$ & $4,05 \%$ & $2,80 \%$ \\
\hline 861,32 & 799,68 & 868,97 & 878,00 & $1,90 \%$ & $8,92 \%$ & $0,60 \%$ \\
\hline 985,97 & 880,63 & 1037,35 & 1083,00 & $8,96 \%$ & $18,69 \%$ & $3,23 \%$ \\
\hline \multicolumn{4}{|c|}{ Jumlah error } & $66,46 \%$ & $86,89 \%$ & $38,27 \%$ \\
\hline \multicolumn{4}{|c|}{ Error rata-rata } & $6,65 \%$ & $8,69 \%$ & $3,83 \%$ \\
\hline
\end{tabular}

Data pada tabel dapat dilihat bahwa hasil nilai TDS yang paling mendekati nilai pada alat acuan yaitu sensor konduktivitas elektroda berbentuk plat tipis karena luas bidang yang berhadapan antar elektrodanya lebih besar dibandingkan dengan silinder pejal dan silinder berongga. Hal ini dibuktikan dengan error rata-rata yang didapatkan pada plat tipis sangat kecil yaitu sebesar 3,83\% sedangkan error yang didapatkan pada silinder pejal dan silinder berongga berturut-turut yaitu 6,65\% dan 8,69\%. Nilai error yang kecil membuktikan bahwa nilai yang telah diukur mendekati nilai yang sebenarnya pada alat acuan. Gambar 7 dapat menjelaskan nilai TDS pada alat penelitian dibandingkan dengan alat acuan.

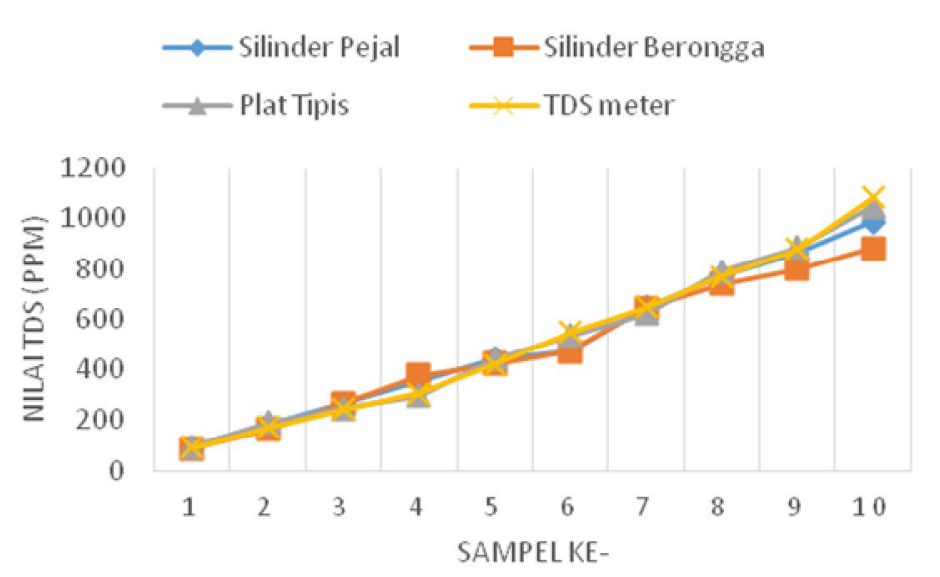

Gambar 7 Grafik perbandingan nilai TDS pada alat acuan dengan alat penelitian

Pada Gambar 7 terlihat bahwa pada grafik sensor konduktivitas elektroda berbentuk plat tipis dengan alat acuan hampir sama pada semua titik yang artinya memiliki nilai yang hampir sama. Pada grafik silinder pejal dan silinder berongga memiliki nilai yang jauh berbeda dengan nilai TDS pada alat acuan.

\subsection{Hasil Pengujian Hubungan Temperatur Terhadap TDS}

Pada pengujian pengaruh temperatur terhadap TDS didapatkan hasil yang memperlihatkan bahwa nilai TDS berfluktuasi terhadap temperatur, seperti ditunjukkan Gambar 8. Variasi temperatur yang digunakan pada pengujian ini yaitu $25^{\circ} \mathrm{C}$ hingga $87^{\circ} \mathrm{C}$. 


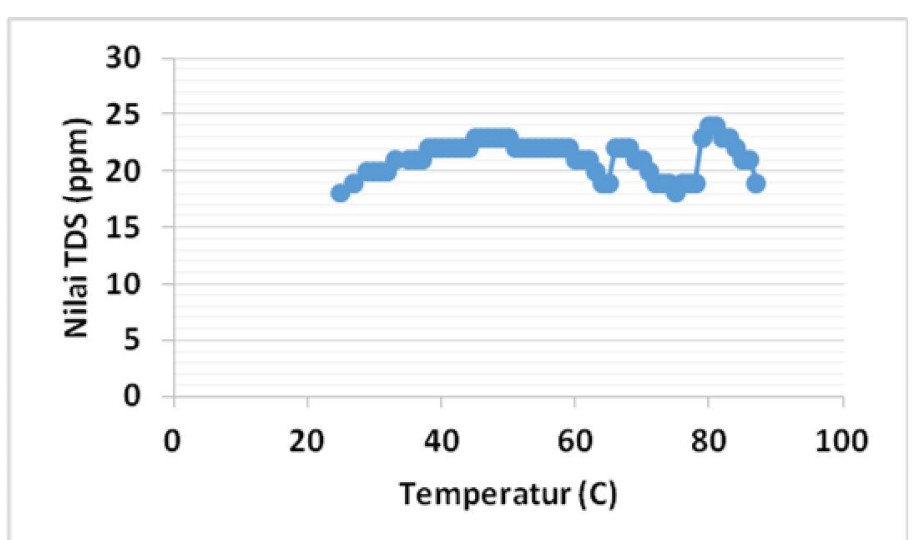

Gambar 8 Grafik hubungan nilai TDS alat acuan terhadap temperatur.

Nilai TDS yang terbaca bervariasi antara 18 ppm hingga 24 ppm. Hal ini terjadi karena transfer kalor pada zat cair bersifat konveksi dimana kalor mengalir bersama-sama dengan mediumnya. Dengan kata lain, jumlah zat terlarut yang diindera sensor juga fluktuatif tetapi dalam batas-batas tertentu. Hal ini diperkuat dengan kenyataan bahwa hasil yang diperoleh dari pengukuran nilai TDS dengan menggunakan alat ukur acuan TDS meter EZ-1 juga bersifat fluktuatif.

\section{KESIMPULAN}

Hasil pengukuran TDS dengan menggunakan sensor konduktivitas dengan tiga bentuk elektroda didapatkan hasil yang paling mendekati nilai pada alat acuan adalah sensor konduktivitas elektroda berbentuk plat tipis. Error yang didapatkan untuk masing-masing bentuk elektroda silinder pejal, silinder berongga dan plat tipis berturut-turut adalah $6,65 \%$, $8,69 \%$ dan $3,83 \%$. Perubahan temperatur dalam air minum kemasan (dari $25^{\circ} \mathrm{C}$ hingga $84^{\circ} \mathrm{C}$ ) menyebabkan nilai TDS berfluktuasi antara 18 ppm hingga 24 ppm.

\section{DAFTAR PUSTAKA}

Devi Luh PWK, Dharma P dan Bawa P. 2013. Efektifitas Pengolahan Air Reklamasi di Instalasi Pengolahan Air Limah Suwung Denpasar Ditinjau dai kandungan Kekeruhan, Total Zat terlarut (TDS), dan Total Zat Tersuspensi (TSS). Jurnal Kimi, Vol 7 No. 1, Hal 64-74.

Kementerian Kesehatan, 2010, Undang-undang Nomor 492 Tahun 2010 tentang Persyaratan Kualitas Air Minum, Jakarta.

Sawyer, C. N., 1994. Chemistry For Environmental Engeneering, Fourth Edition. McGraw-Hill Inc, Singapore.

WHO, 2003. Total dissolved solids in Drinking-water. World Health Organization, Geneva, Switzerland.

YLKI, 2011, Waspadai Air Minum Dalam Kemasan, http://www.ylki.or.id, diakses Februari,2016. 